\title{
Congenital cardiac surgery fellowship training: A status update
}

\author{
Brian Kogon, MD, ${ }^{\mathrm{a}}$ Tara Karamlou, MD, ${ }^{\mathrm{b}}$ William Baumgartner, MD,${ }^{\mathrm{c}}$ Walter Merrill, MD, ${ }^{\mathrm{d}}$ and \\ Carl Backer, MD
}

\section{ABSTRACT}

Background: In 2007, congenital cardiac surgery became a recognized fellowship by the Accreditation Council of Graduate Medical Education (ACGME) and leads to board certification through the American Board of Thoracic Surgery (ABTS). We highlight the strengths and weaknesses in the current system of accredited training.

Methods: Data were collected from program directors, the ACGME, and the ABTS. In addition, surveys were sent to training program graduates. Topics included program accreditation status, number of fellows trained per year and per program, match results, fellow operative experience, fellow satisfaction, and post-fellowship employment status.

Results: There are twelve active accredited fellowship programs, and 44 trainees have completed accredited training. Each active program has trained a median of 3 fellows (range: 0-7). Operative logs were obtained from 38 of $44(86 \%)$ graduates. The median number of total cases (minimum 75) was 136 (range: 75-236). For complex neonates (minimum 5), the median number of cases was 6 (range: 2-17). Some fellows failed to meet the minimum requirements. Thirty-six (82\%) graduates responded to the survey; most were satisfied with their overall operative experience, but less with their neonatal operative experience. Of this total, $84 \%$ are currently practicing congenital cardiac surgery, and $74 \%$ secured jobs prior to completing their residency.

Conclusions: Since 2007, congenital cardiac surgery training has been accredited by the ACGME. In general, the training is uniform, the operative experience is robust, and the fellows are satisfied. Although shortcomings remain, this study highlights the many strengths of the current system. (J Thorac Cardiovasc Surg

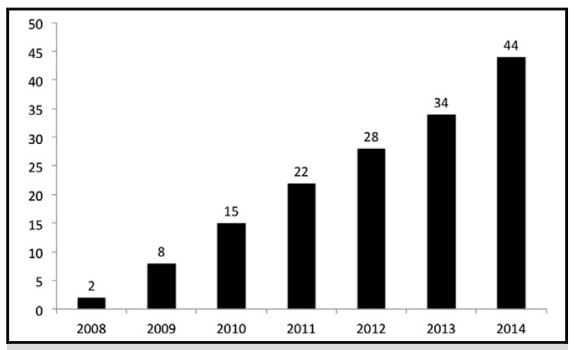

Cumulative number of congenital cardiac surgery trainees since ACGME accreditation began in 2007.

\section{Central Message}

With ACGME accreditation, congenital cardiac surgery training is robust; most graduates are well trained, satisfied, and thriving.

\section{Perspective}

Since ACGME accreditation began, congenital cardiac surgery training has been standardized. Fellows are operating and satisfied. A good balance has been achieved between the number of job openings and the number of graduating trainees. Recent graduates seem to be thriving in practice. Nonetheless, shortcomings remain, and our intention with this study is to highlight these issues and stimulate future improvements.

See Editorial Commentary page 1496. 2016;151:1488-95)

The training of congenital heart surgeons is extremely complex. In 2005, we surveyed graduates of congenital cardiac surgery training fellowship programs. ${ }^{1}$ The number of operations performed by the fellows during their training was underwhelming, and most of the fellows were dissatisfied with their operative experience. ${ }^{1}$

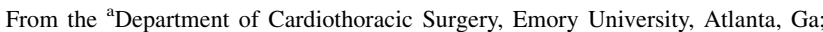
${ }^{b}$ Department of Cardiothoracic Surgery, University of California San Francisco,

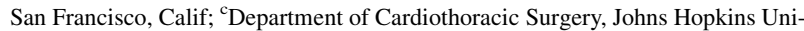
versity, Baltimore, Md; ${ }^{\mathrm{d}}$ Department of Cardiac Surgery, Vanderbilt University Medical Center, Nashville, Tenn; and ${ }^{\mathrm{e}}$ Department of Cardiothoracic Surgery, Northwestern University, Chicago, Ill.

Read at the 41st Annual Meeting of The Western Thoracic Surgical Association, Whistler, British Columbia, Canada, June 24-27, 2015.

Received for publication April 22, 2015; revisions received Sept 9, 2015; accepted for publication Feb 7, 2016; available ahead of print March 18, 2016.

Address for reprints: Brian Kogon, MD, Emory University, Egleston, Atlanta, GA (E-mail: Bkogon@emory.edu).

0022-5223/\$36.00

Copyright (c) 2016 by The American Association for Thoracic Surgery

http://dx.doi.org/10.1016/j.jtcvs.2016.02.039
}

In 2007, congenital cardiac surgery became a recognized fellowship by the Accreditation Council of Graduate Medical Education (ACGME). Program and fellowship training requirements are now in place, and training leads to American Board of Thoracic Surgery subspecialty certification. We aim to highlight the strengths and weaknesses in the current system of congenital cardiac surgical training, as well as compare specific metrics of the pre- versus post-accreditation training eras.

Specific topics include the following: program entrance and exit into providing accreditation; number of

Scanning this QR code will take you to the article title page.

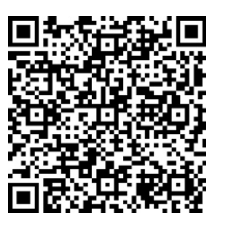


Abbreviations and Acronyms

ACGME $=$ Accreditation Council of Graduate

Medical Education

CI $\quad=$ confidence interval

fellows trained per year and per program; match results; fellow operative experience; fellow satisfaction with training; and postfellowship employment status and case mix. Although congenital cardiac trainees who are in ACGME-accredited training programs typically are referred to as residents, we refer to them as fellows in this article, in keeping with historical precedent.

\section{METHODS}

Data were collected from various sources to address each topic. The ACGME website provided a list of accredited programs, the dates of program entrance and exit into accreditation, and the names of the program directors. ${ }^{2-4}$ The individual program directors provided the names of the fellows, as well as the number trained per year and per program. The Thoracic Surgery Directors Association provided results from the congenital cardiac surgery match, and the American Board of Thoracic Surgery provided board certification status. Individual fellows and/or program directors provided operative logs.

A survey sent to all 44 graduates provided information regarding demographics, satisfaction with training, and postfellowship employment status. The online, cross-sectional survey included nominal and ordinal polytomous, dichotomous, and bounded continuous response formats. An initial letter was sent to the graduates, as a preamble to the survey, as a mechanism to increase participation. The surveys were first sent on October 31, 2014; subsequent reminders were sent to nonresponders on November $8(\mathrm{n}=26)$, December $6(\mathrm{n}=13)$, and January 25, 2015 $(\mathrm{n}=10)$. The survey was closed on January 30,2015 , with a total of 8 nonresponders.

For data collection and presentation, anonymity was promised and delivered to the fellows and program directors; the primary author, however, had participant identifier information access, for cataloguing reasons only. Summary statistics were applied throughout. When appropriate, specific tests for correlation were performed.

\section{RESULTS}

\section{Program Status Entrance and Exit, and Number Trained}

Twelve accredited programs are currently active (13 gained accreditation over the course of 8 years; 1 later withdrew; Table 1). The timeline of cumulative program accreditation is shown in Figure 1. Forty-four trainees have completed an accredited fellowship program. Of the active programs, each has trained a median of 3 fellows (range: 0-7). The timeline of cumulative fellow graduation is shown in Figure 2.

\section{Match Results}

In the match for the 2014-2015 academic year, 6 of 12 programs waived participation. Three individuals applied for the 6 available positions, all of whom were successfully matched, leaving 3 participating programs without a matched applicant. In the match for the 2015-2016 academic year, 7 of 12 programs waived or withdrew from participation. Seven individuals applied for the 5 available positions, 5 of whom were successfully matched, leaving 2 unmatched applicants and no participating programs without a matched applicant. In the match for the 2016-2017 academic year, waiving the match will not be allowed. A summary of these results is shown in Table 2.

\section{Board Certification Status}

Details surrounding the fellows' eligibility and process toward certification are shown in Figure 3. Of the 44 graduates, 8 are not eligible, or have not applied for board certification. Of these, 4 have not yet completed the requirements for primary thoracic board certification; 3 have completed primary certification, but their current status is unknown, and 1 died. Thirty-six have applied for certification. In total, only 22 of $44(50 \%)$ are certified, meaning they have passed both the written qualifying and oral certifying examinations.

\section{Fellow Operative Experience}

Operative logs were obtained from 38 of $44(86 \%)$ graduates. Twenty-nine logs were received from the program directors, and 14 from the individual fellows, resulting in dual reporting for 5 of the graduates. A summary of the fellows' operative logs (Table 3 ) shows that the median number of total cases (minimum requirement of 75) was 136 (range: 75-236). The median number of specific qualifying cases (minimum requirement of 32) was 63 (range: 39-148). For complex neonates (combined minimum requirement of 5), the median number of cases was 6 (range: 2-17).

Some residents failed to meet the minimum requirements. Failure to meet operative requirements occurred in each of the following categories: atrioventricular septal defect repair, arch reconstruction including coarctation procedures, systemic-to-pulmonary artery shunt procedures, and complex neonatal procedures. No correlation was found between program volume (median 850; range: 350-1250) and fellow case volume ( $\mathrm{r}=0.23 ; P=.17,95 \%$ confidence interval $[\mathrm{CI}]:-0.11$ to 0.53 ).

\section{Fellow Survey}

Demographics and prefellowship. A total of $36(82 \%)$ graduates responded to the survey. Men comprised $83 \%$, and the median age at graduation was 40 (range: 35-48) years. Identifying with a mentor was the most common initial experience that motivated graduates to pursue a career in congenital cardiac surgery (Table 4). 
TABLE 1. List of programs

\section{Program name/location}

Baylor College of Medicine/Texas Heart Institute

Children's Hospital/Massachusetts General Hospital/Boston Children's Hospital

Children's Healthcare of Atlanta/Emory University

McGaw Medical Center of Northwestern University/Lurie Children's Hospital

Medical College of Wisconsin Affiliated Hospitals

Nationwide Children's Hospital/Ohio State University*

Stanford University

UCLA Medical Center

University of Colorado

University of Michigan

University of Pennsylvania/Children's Hospital of Philadelphia

University of Southern California/Children's Hospital of Los Angeles

University of Washington

UCLA, University of California Los Angeles. *Withdrew from providing accreditation.

Fellowship. On a scale of 1 to $5(1=$ strongly disagree; $2=$ disagree; $3=$ undecided; $4=$ agree; $5=$ strongly agree), most graduates were satisfied with their overall training experience (average score: 4.43). In particular, they were satisfied with their operative experience as "primary surgeon" (average score: 4.14), and their operative experience as "first assistant" (average score: 4.69). They were slightly less satisfied with their complex neonatal operative experience (average score: 3.78). Most graduates said they would recommend fellowship training to those interested, as well as the program in which they had trained (average scores: 4.69 and 4.51, respectively).
Correlations were found between operative satisfaction and fellow case volume $(\mathrm{r}=0.48,95 \% \mathrm{CI}=0.18-0.70$; $P=.005)$, as well as overall satisfaction and fellow case volume $(\mathrm{r}=0.35,95 \% \mathrm{CI}=0.01-0.61 ; P=.04)$. No correlation was found between overall satisfaction and whether the postfellowship graduate was performing congenital cardiac surgeries $(\mathrm{r}=0.13,95 \% \mathrm{CI}=-0.22$ to $0.44 ; P=.46$ ), nor how long the fellow took to find postgraduate employment $(\mathrm{r}=0.12,95 \% \mathrm{CI}=-0.22$ to $0.45 ; P=.48$ ). Only $25 \%$ of graduates participated in nonsurgical rotations (ie cardiac catheterization, echocardiography, and cardiac magnetic resonance imaging/ computed tomography) during their fellowship. Although $61 \%$ of graduates followed a formal curriculum, only $28 \%$ used the Thoracic Surgery Directors Association curriculum. Only $50 \%$ of those who used either curriculum found it helpful (Table 5).

Postfellowship. Of the respondents, $85 \%$ are currently practicing within the subspecialty of congenital cardiac surgery ( $>75$ major cases per year, of which $>75 \%$ are congenital). Most $(76 \%)$ are in non-solo academic practices, and $76 \%$ secured jobs before completing their fellowship. The average annual case volume is 170 , with an average mortality category distribution (per the Society of Thoracic Surgeons/European Association of Thoracic Surgery) as follows (category, with percentage): $1: 25 \%$; 2: $30 \%$; 3: 20\%; 4: 16\%; and 5: 9\% (Table 6).

\section{DISCUSSION}

\section{The ACGME and the American Board of Thoracic} Surgery

Congenital cardiac surgery is currently an ACGMEcertified fellowship, with the first programs entering

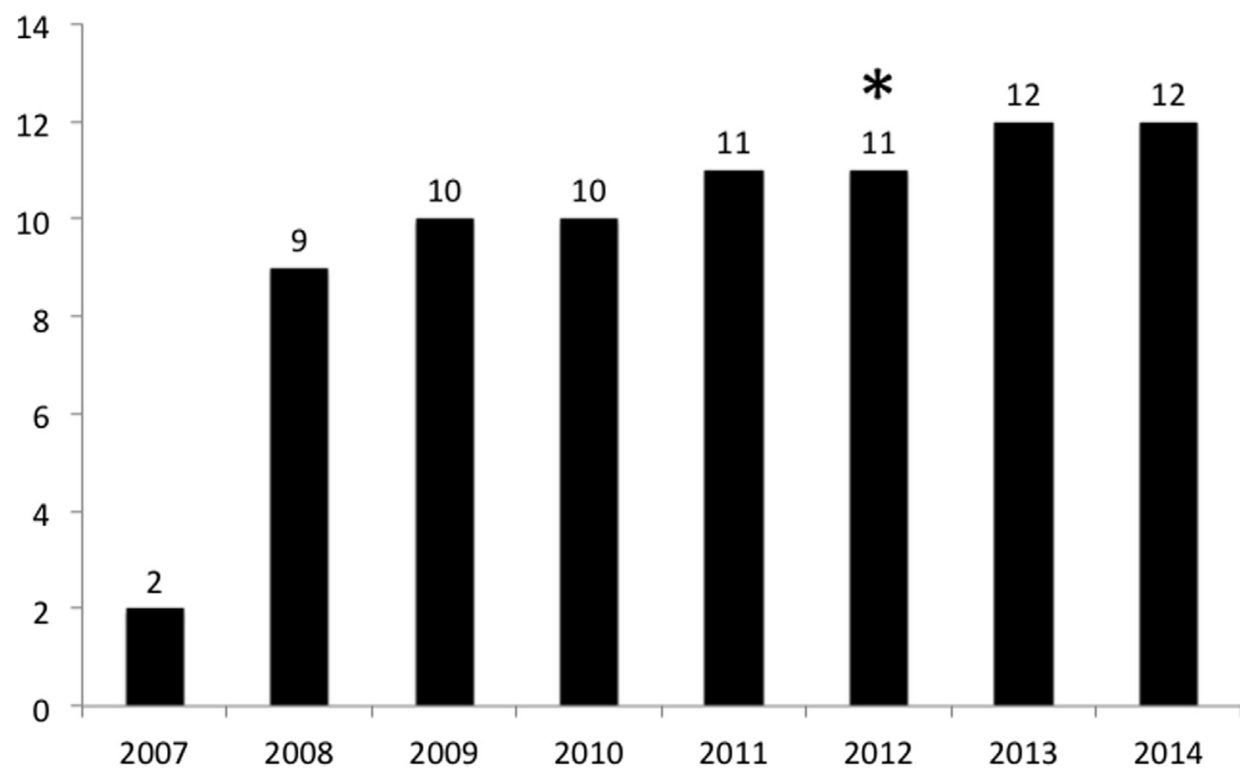

FIGURE 1. Cumulative number of accredited programs per year. *2012: One additional accredited program and one withdrawal. 


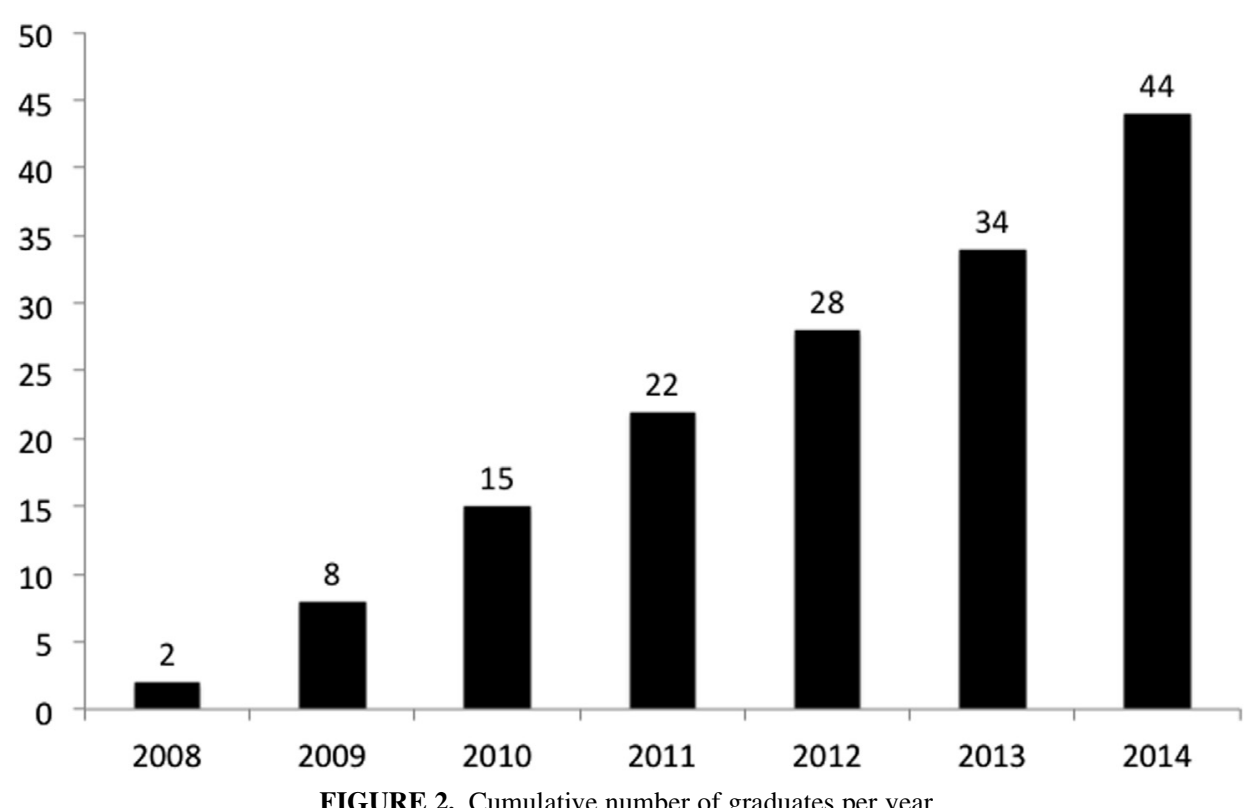

accreditation in 2007. This accreditation process allows for standardization and regulation of fellowship training. ${ }^{5}$ Programs are required to have a single program director and sufficient numbers of qualified faculty to instruct and supervise fellows. Fellows are required to meet criteria within the 6 core competencies. Processes are required to serially evaluate the fellow, the faculty, and the program; policies are required to address duty hours, transitions of care, alertness management/fatigue mitigation, and fellow supervision.

For procedural skills, the current operative requirements include a minimum of 75 major congenital cases, and the following minimum numbers of specific qualifying cases: ventricular septal defect (5); atrioventricular septal defect repairs (4); tetralogy of Fallot (4); arch reconstruction including coarctation procedures (4); arterial switch/Norwood/Damus Kaye Stansel/truncus arteriosus repairs (any combination up to a total of 5); Glenn/

TABLE 2. Congenital cardiac surgery fellowship match history

\begin{tabular}{lcc}
\hline & \multicolumn{2}{c}{ Academic year } \\
\cline { 2 - 3 } \multicolumn{1}{c}{ Variable } & $\mathbf{2 0 1 4 - 2 0 1 5}$ & $\mathbf{2 0 1 5 - 2 0 1 6}$ \\
\hline Number of programs & 12 & 12 \\
Program withdrawals & 0 & 1 \\
Program waivers* & 6 & 6 \\
Participating programs & 6 & 5 \\
Match applications & 3 & 7 \\
Applicant withdrawals & 0 & 0 \\
Fellowship positions filled through the match & 3 & 5 \\
Unmatched participating programs & 3 & 0 \\
Unmatched participating applicants & 0 & 2 \\
\hline
\end{tabular}

*2015-2016 was the final year for program waivers.
Fontan procedures (5); and systemic-to-pulmonary artery shunt procedures (5). ${ }^{6}$ Twelve programs are currently ACGME-accredited training programs in congenital cardiac surgery.

In 2009, the American Board of Thoracic Surgery began offering a subspecialty certificate in congenital cardiac surgery. For fellows who trained prior to July 1, 2008, a previously existing "grandfather" pathway allowed for certification. ${ }^{7}$ For fellows trained after July 1, 2008, subspecialty certification in congenital cardiac surgery may be achieved by fulfilling the following requirements: achieving primary certification by the American Board of Thoracic Surgery; successfully completing an ACGME-accredited fellowship and performing the required operative cases; and passing the congenital cardiac surgery written qualifying and oral certifying examinations.?

\section{Progress?}

In 2005, we surveyed graduates of congenital cardiac surgery training fellowships. ${ }^{1}$ The study included fellows who had completed 12 months of pediatric cardiothoracic surgical training within the previous 5 years. Questionnaires were completed using e-mail, mail, or phone correspondence. The questions were focused on the fellows' operative exposure, operative experience, and satisfaction. Twentyeight of $42(67 \%)$ fellows responded, from 11 training programs. Each fellow performed a mean of $75( \pm 53)$ operations. At that time, we categorized operations by the Risk Adjusted Congenital Heart Surgery Score. As the primary surgeon, fellows typically performed operations in categories 1,2, and 3 only. Of the 28 fellows, 7 performed operations in category 4 , none in category 5 , and 1 in category 6 . On a scale of 1 to 10 (with $10=$ being satisfied), 


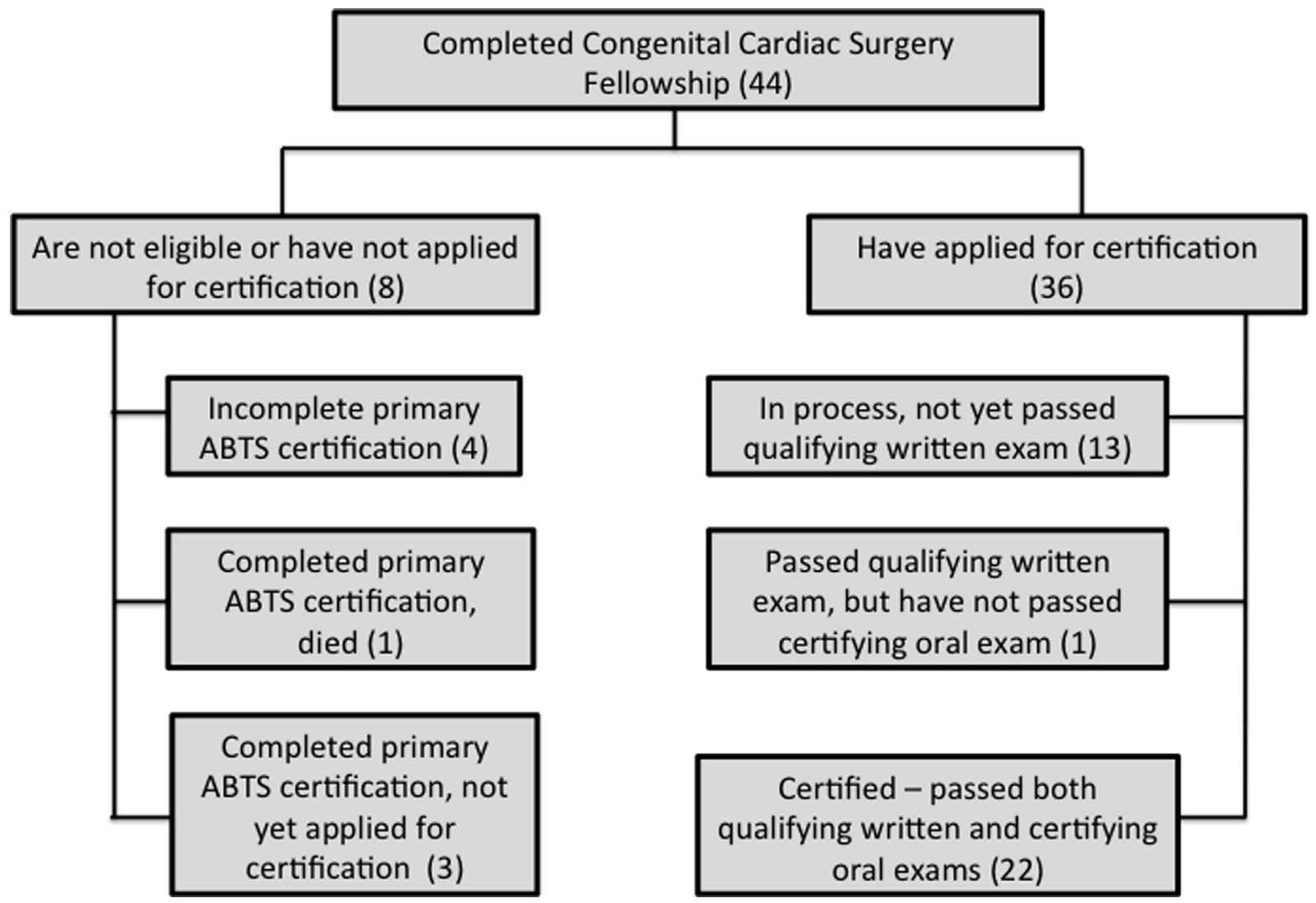

FIGURE 3. Board certification status. ABTS, American Board of Thoracic Surgery.

the trainees were not very satisfied with their operative experience (average score: 4.9).

In the current study, data were collected from various sources. Ultimately, operative $\log$ s were available for 38 of $44(86 \%)$ graduates, and 36 of $44(82 \%)$ responded to the survey. The median number of total cases was 136 (range: 75-236), and the median number of specific qualifying cases was 63 (range: 39-148). In addition, on a scale of 1 to 5 (with $5=$ being satisfied), they were satisfied

TABLE 3. Operative log summary

\begin{tabular}{lccc}
\hline & & \multicolumn{2}{c}{ Fellows, $\mathbf{n}$} \\
\cline { 3 - 4 } \multicolumn{1}{c}{ Operative case } & ABTS requirement & Median & Range \\
\hline VSD & 5 & 15 & $5-45$ \\
AVSD & 4 & 6 & $3-14$ \\
TOF & 4 & 7 & $4-19$ \\
Arch repair/coarctation & 4 & 7 & $3-23$ \\
Shunt & 5 & 6 & $0-29$ \\
Glenn/Fontan & 5 & 14 & $7-50$ \\
Complex neonates* & 5 & 6 & $2-17$ \\
Total index cases & 32 & 63 & $39-148$ \\
Total cases & 75 & 136 & $75-236$ \\
\hline ABTS, American Board of Thoracic Surgery; $V S D$, ventricular septal defect; \\
AVSD, atrioventricular septal defect; TOF, tetralogy of Fallot. *Arterial switch, \\
Damus-Stansel-Kaye, Norwood, truncus arteriosus.
\end{tabular}

with their operative experience as "primary surgeon" (average score: 4.14), and their operative experience as "first assistant" (average score: 4.69). They were slightly less satisfied with their complex neonatal operative experience (average score: 3.78), although 88\% succeeded in meeting the index requirement (5) for complex neonates.

Although the operative experience seems to be much more robust, and this finding has been corroborated in other surgical disciplines after the advent of ACGME

TABLE 4. Survey results: demographics and pre-fellowship

\begin{tabular}{lc}
\hline \multicolumn{1}{c}{ Survey topic } & $\mathbf{n}(\%)$ \\
\hline Demographics & \\
Gender & $30(83)$ \\
Male & $6(17)$ \\
Female & $36.9 \pm 2.2$ \\
Age at graduation, mean (y) & \\
Pre-fellowship & \\
Experience that most motivated graduates to pursue & \\
$\quad$ a career in congenital cardiac surgery & $10(28)$ \\
Mentor & $5(14)$ \\
Medical student rotation & $6(17)$ \\
Resident rotation & $9(25)$ \\
Viewing surgery & $6(17)$ \\
Other &
\end{tabular}




\begin{tabular}{|c|c|c|}
\hline Survey topic & n $(\%)$ & $\begin{array}{c}\text { Average score } \\
\text { (Scale: 1-5) }\end{array}$ \\
\hline \multicolumn{3}{|l|}{ Satisfaction } \\
\hline I was satisfied with the operative experience as "primary surgeon" & & 4.14 \\
\hline I was satisfied with the complex neonatal operative experience & & 3.78 \\
\hline I was satisfied with the operative experience as "first assistant" & & 4.69 \\
\hline I performed enough adult congenital operations to be comfortable & & 4.00 \\
\hline I completed all of the operative requirements & $32(89)$ & \\
\hline I was satisfied with the overall training experience & & 4.43 \\
\hline My fellowship prepared me for independent practice & & 4.00 \\
\hline I would recommend ACGME fellowship training to those interested & & 4.69 \\
\hline I would recommend the ACGME fellowship in which I trained & & 4.51 \\
\hline \multicolumn{3}{|l|}{ Program structure } \\
\hline I had an identifiable mentor during the fellowship & & 4.50 \\
\hline My fellowship included nonsurgical rotations (catheterization, echocardiography, MRI/CT) & $9(25)$ & \\
\hline My fellowship used a formal curriculum & $22(61)$ & \\
\hline My fellowship used the TSDA weekly curriculum & $10(28)$ & \\
\hline The curriculum was helpful & $18(50)$ & \\
\hline I participated in scholarly activity (published study) during fellowship & $30(83)$ & \\
\hline
\end{tabular}

accreditation, comparing training before and after the accreditation process came into existence is difficult. ${ }^{8-10}$ For example, various programs and fellows were included in our 2 separate studies. Previously, some institutions may have trained multiple fellows, and the duration was variable, potentially affecting training and satisfaction. In addition, the expectations between the faculty and fellow may have been misaligned previously. Last, in the current era, institutional incentives, owing to risk of losing program accreditation or fellow board eligibility. may lead to overestimation of fellow involvement.

\section{Questions Raised by the Survey}

How do we attract the best and brightest students and residents to a career in congenital cardiac surgery? In this study, identification with a mentor is the most common motivating factor for pursuing this career. However, mentorship likely is correlated with exposure to the subspecialty, either from shadowing practicing congenital surgeons, viewing surgery, or participating in congenital cardiac surgical rotations. Gaining access to congenital surgeons before they develop other interests remains challenging, owing to the intense subspecialization of our field.

Based on a thoracic surgery workforce report, the decision to pursue a career in thoracic surgery was made before or during medical school by $45.3 \%$ of surgeons. ${ }^{11}$ In addition, recent studies have shown that structured programs that introduce medical students to cardiothoracic surgery can improve recruitment into surgical careers. ${ }^{12}$ Early exposure to the subspecialty may be increasingly important, particularly with the shorter training offered through the integrated 6-year programs.

\section{Have U.S. Program Graduates Stopped Seeking Additional International Training?}

A large proportion of the American leaders in our field in the past several decades can trace their early career paths back to important clinical fellowships undertaken in various places around the world. ${ }^{13}$ Unfortunately, since the initiation of accredited training, few graduates from the United States have trained at Great Ormand Street Hospital for Sick Children in London, the Royal Children's Hospital in Melbourne, or other international institutions that have a history of strong congenital cardiac surgery training programs. $^{13}$ This change places us at risk of becoming intellectually isolated and losing international relationships that are critical to the future of our specialty. ${ }^{13}$

Are we training an appropriate number of congenital cardiac surgeons? One of the deterrents from pursuing a career in cardiac surgery, particularly congenital cardiac surgery, traditionally has been the difficulty in finding a job after so many years of training. The number of congenital heart surgery jobs in North America seems to be relatively stable across years. The 2011 directory of congenital cardiac care providers in North America listed 127 hospitals that were providing open surgery of the heart for children, and 258 congenital heart surgeons. ${ }^{14}$ The 2014 revised version of the directory listed 118 hospitals and 253 surgeons.

Studies ${ }^{15,16}$ examining the congenital cardiac surgery workforce were published in 2006 and 2011, respectively. In the 2006 study, 3 congenital surgeons were anticipating retirement within 1 year; at the same time, 39 fellows 
TABLE 6. Survey results: postfellowship

\begin{tabular}{|c|c|c|}
\hline Survey topic & n $(\%)$ & Mean \pm SD \\
\hline \multicolumn{3}{|l|}{$\begin{array}{l}\text { How long I searched after fellowship for } \\
\text { employment as a congenital } \\
\text { cardiac surgeon }(\mathrm{n}=35)\end{array}$} \\
\hline Prior to starting & $5(14)$ & \\
\hline Prior to completing & $21(60)$ & \\
\hline $0-3(\mathrm{mo})$ & $1(3)$ & \\
\hline 3-6 (mo) & $2(6)$ & \\
\hline $6-12(\mathrm{mo})$ & $3(9)$ & \\
\hline $1-2(y)$ & $1(3)$ & \\
\hline$>2(\mathrm{y})$ & $2(6)$ & \\
\hline $\begin{array}{l}\text { I am currently practicing congenital cardiac } \\
\text { surgery }(>75 \text { major cases } / y,>75 \% \text { are } \\
\text { congenital cases })(n=33)\end{array}$ & $28(85)$ & \\
\hline \multicolumn{3}{|l|}{ My current practice setting $(\mathrm{n}=34)$} \\
\hline Private practice: solo & $1(3)$ & \\
\hline Private practice: non-solo & $5(15)$ & \\
\hline Academic, community based & $2(6)$ & \\
\hline Academic, university based: solo & 0 & \\
\hline Academic university based: non-solo & $26(76)$ & \\
\hline The number of facilities at which I operate & & $1.5 \pm 0.7$ \\
\hline My annual case load & & $170 \pm 62$ \\
\hline$\%$ of my cases that are pediatric congenital cases & & $81.4 \pm 24.5$ \\
\hline$\%$ of my cases that are neonatal $(<1 \mathrm{mo})$ & & $30.3 \pm 16.2$ \\
\hline$\%$ of my cases that are adult congenital cases & & $18.0 \pm 15.3$ \\
\hline \multicolumn{3}{|l|}{$\%$ of my cases yearly in each STAT mortality category } \\
\hline 1 & & $25.0 \pm 12.5$ \\
\hline 2 & & $29.5 \pm 11.3$ \\
\hline 3 & & $20.4 \pm 8.8$ \\
\hline 4 & & $16.2 \pm 8.7$ \\
\hline 5 & & $9.3 \pm 7.6$ \\
\hline $\begin{array}{l}\text { I felt the written examination was fair/reasonable } \\
\qquad(\mathrm{n}=29)\end{array}$ & $23(79)$ & \\
\hline $\begin{array}{l}\text { I felt the oral examination was fair/reasonable } \\
\quad(\mathrm{n}=25)\end{array}$ & $20(80)$ & \\
\hline $\begin{array}{l}\text { I have participated in any scholarly activity } \\
\text { (published study) since fellowship }(\mathrm{n}=35)\end{array}$ & $27(77)$ & \\
\hline
\end{tabular}

would complete postgraduate training at 28 centers, and 19 would seek positions in North America. ${ }^{11}$ The 2011 study suggested that 28 practicing congenital heart surgeons planned to retire over the subsequent 5 years, 31 over the subsequent 6-10 years, and 47 over the subsequent 11-15 years. ${ }^{16}$ These numbers create a total of 106 retirees over 15 years, for an average of 7 per year. ${ }^{16}$ These estimates did not include projections of unplanned retirement for health reasons. ${ }^{16}$

In our study, by survey, $84 \%$ of graduates are currently practicing congenital cardiac surgery, and $74 \%$ secured jobs prior to completing their fellowship. However, not all of the congenital training programs have trained a fellow every year thus far. In fact, we have only graduated a median of 6.5 fellows per year (range: 6-10). If the current 12 programs all have 1 fellow graduate in the same year, this volume may be too high and become problematic. Although we may be becoming more closely aligned, options to even better align the number of trainees with the number of job opportunities include increasing the minimum case volume requirements, so that fewer institutions have training programs, and creating a rotating schedule for the accredited programs so that every program does not train a fellow every year.

What factors play a role in fellow satisfaction? Fellow satisfaction clearly is affected by operative experience, as shown by correlations between operative satisfaction, as well as overall satisfaction, and fellow case volume. Whether other factors may affect satisfaction, particularly in situations in which the operative experience was not robust, is unclear. No correlation was found between overall satisfaction and whether the postfellowship graduate was performing congenital cardiac surgery, or how long it took the fellow to find postgraduate employment.

Are the fellows successful after gaining employment? In the 2006 congenital cardiac surgery workforce study, only 128 of $217(59 \%)$ surgeons performed exclusively congenital heart surgery. ${ }^{15}$ One third performed $<100$ congenital cases per year; one third performed 100 to 199 ; and one third performed $\geq 200 .{ }^{15}$ Only $69 \%$ were engaged in clinical research. ${ }^{15}$

In our study, $91 \%$ of graduates were in non-solo practices ( $76 \%$ academic and $15 \%$ private), thereby having access to partners and mentors. The average volume of 170 cases per year is very respectable, as is the average Society of Thoracic Surgeons/European Association of Thoracic Surgery mortality case mix, and $77 \%$ of graduates are participating in research activity. Clinical exposure to the full spectrum of congenital heart surgery, as mandated by the ACGME fellowship, is likely to have a direct and enduring impact on future case mix and scope. A survey of hand surgeons showed that differences in clinical exposure during ACGME fellowships were reflected in later clinical practice, and persisted over time, despite similar practice settings. ${ }^{8}$

Should we be concerned that very few of the cases being done by congenital heart surgeons are adult congenital cases? The number of adults who have congenital heart disease now exceeds the number of children who have the disease, and many of these patients will require an operation. Information obtained from the Society of Thoracic Surgeons Adult Cardiac Surgery Database suggests that a very large number of surgeons $(>1000)$, who do primarily cardiac surgery on adults with acquired heart disease, account for numerous adult congenital heart surgery cases per year. ${ }^{15}$ Unfortunately, data additionally suggest that outcomes may be better when these adult congenital cases are performed by congenitally trained cardiac surgeons. ${ }^{17,18}$ Whether this difference is related directly to congenital cardiac training, the ongoing 
exposure to congenital heart surgery, or a combination of both, is unclear. A greater interest in these patients from congenital heart surgery programs may be optimal for both the patients and the surgeons, particularly by providing a unique opportunity for new graduates.

\section{Is There an Optimal Curriculum for Congenital Cardiac Surgery Training?}

The Thoracic Surgery Directors Association Congenital Curriculum is based on a 1-year, 32-week lesson plan and is designed for congenital cardiothoracic surgery fellows. ${ }^{19}$ Weekly assignments supplement a fellow's program curriculum and include basic readings. ${ }^{19}$ According to our survey, only $61 \%$ of trainees used a formal curriculum, and only $28 \%$ used the Thoracic Surgery Directors Association weekly curriculum. Unfortunately, regardless of the curriculum, only $50 \%$ found it helpful. The enormous amount of time and effort spent maintaining and updating this weekly curriculum may not be worthwhile. On the other hand, only $50 \%$ of the graduates have passed the written qualifying and oral certifying examinations. Although the curriculum is quite robust, the latter statistic suggests that we need either more emphasis on education by the program directors or a better and/or different curriculum. Passive, didactic instruction may not be well suited for advanced learners; rather, a more interactive format may be a better choice.

\section{Limitations}

This study has several limitations. First, we had access to only $86 \%$ of the fellows' operative logs, and only $82 \%$ of the residents responded to the survey. The residents who had the worst operative experiences and the worst training experiences may have been the most reluctant to share their operative logs and opinions. In addition, the operative logs were self-reported, but we found the 5 operative logs that were dually submitted by the fellows and the program directors to be reassuringly similar. Other limitations, particularly with regard to comparison of our previous and current studies, are highlighted in the Discussion.

\section{CONCLUSIONS}

In the current system of accreditation, congenital cardiac surgery training is robust. Fellowships in congenital heart surgery have been standardized. Fellows are performing numerous operations, particularly complex ones, and are satisfied with their training. A good balance is provided between the number of yearly job openings and the number of graduating trainees. After training, former fellows have adequate case volumes and mixes and seem to be thriving in the field. Nonetheless, shortcomings remain, and our intention is to highlight these issues and stimulate future improvements.

\section{Conflict of Interest Statement}

Authors have nothing to disclose with regard to commercial support.

\section{References}

1. Kogon BE. The training of congenital heart surgeons. J Thorac Cardiovasc Surg. 2006;132:1280-4.

2. Accreditation Council for Graduate Medical Education. List of programs by specialty. Available at: www.acgme.org/ads/Public/Reports/Report/1. Accessed April 21, 2015.

3. Accreditation Council for Graduate Medical Education. List of newly accredited programs (based on academic year or date). Available at: www.acgme.org/ads/ Public/Reports/Report/8. Accessed April 21, 2015.

4. Accreditation Council for Graduate Medical Education. List of withdrawn programs. Available at: www.acgme.org/ads/Public/Reports/Report/7. Accessed April 21, 2015.

5. Accreditation Council for Graduate Medical Education. Common program requirements for one year fellowships. Available at: www.acgme.org/ acgmeweb/Portals/0/PDFs/One_Year_CPRs_Categorization_07012013.pdf. Accessed April 21, 2015.

6. American Board of Thoracic Surgery. Pathway one: subspecialty certification for candidates trained after July 1, 2008. Available at: www.abts.org/root/home/ congenital-cardiac-subspecialty/pathway-one.aspx. Accessed April 21, 2015.

7. American Board of Thoracic Surgery. Congenital cardiac surgery subspecialty certification. Available at: www.abts.org/root/home/congenital-cardiacsubspecialty.aspx. Accessed April 21, 2015.

8. Mehta K, Pierce P, Chiu DT, Thanik V. The effect of residency and fellowship type on hand surgery clinical practice patterns. Plast Reconstr Surg. 2015;135: 179-86.

9. Franz RW. General versus vascular surgeon: impact of a vascular fellowship on clinical practice, surgical case load, and lifestyle. Ann Vasc Surg. 2010;24: 196-204.

10. Park A, Kavic SM, Lee TH, Heniford BT. Minimally invasive surgery: the evolution of fellowship. Surgery. 2007;142:505-11.

11. Shemin RJ, Ikonomidis JS. The thoracic surgery workforce: report of STS/AATS thoracic surgery practice and access taskforce-snapshot 2010. Ann Thorac Surg. 2012;93:348-55.

12. Haggerty KA, Beaty CA, George TJ, Arnaoutakis GJ, Baumgertner WA. Increased exposure improves recruitment: early results of a program designed to attract medical students into surgical careers. Ann Thorac Surg. 2014;97: 2111-4.

13. Fraser CD. Preserving our international heritage of education in congenital heart surgery. J Thorac Cardiovasc Surg. 2014;148:377-8.

14. Congenital Cardiology Today. Congenital cardiac care providers in North America at hospitals that offer open heart surgery for children. Available at: www.congenitalcardiologytoday.com/index_files/CCT-DIR-2014.pdf. Accessed April 21, 2015.

15. Jacobs M, Mavroudis C, Jacobs J, Tchervenkov C, Pelletier G. Report of the 2005 Society of Thoracic Surgeons Congenital Heart Surgery Practice and Manpower Survey. Ann Thorac Surg. 2006;82:1152-9.

16. Jacobs ML, Daniel M, Mavroudis C, Morales DL, Jacobs JP, Fraser CD, et al Report of the 2010 Society of Thoracic Surgeons Congenital Heart Surgery Practice and Manpower Survey. Ann Thorac Surg. 2011;92:762-9.

17. Kogon BE, Plattner C, Leong T, Kirshbom PM, Kanter KR, McConnell M, et al. Adult congenital heart surgery: adult or pediatric facility? Adult or pediatric surgeon? Ann Thorac Surg. 2009;87:833-40.

18. Karamlou T, Diggs BS, Person T, Ungerleider RM, Welke KF. National practice patterns for management of adult congenital heart disease: operation by pediatric heart surgeons decreases in-hospital death. Circulation. 2008;118:2345-52.

19. Thoracic Surgery Directors Association. TSDA congenital curriculum. Available at: www.tsda.org/education/tsda-congenital-curricula/. Accessed April 21, 2015.

Key Words: Congenital cardiac surgery, fellowship training 